УДК 781.60

Ольга Альфредовна Нивельт

кандидат искусствоведения, приват-профессор кафедры теории музыки и композиции

Одесской национальной музыкальной

академии имени А. В. Неждановой

odma_n@ukr.net

\title{
О СТИЛЕВОМ ПОДХОДЕ К ИЗУЧЕНИЮ МОДУЛЯЦИЙ В ВУЗОВСКОМ КУРСЕ ГАРМОНИИ
}

Цель статьи. Статья посвящена проблеме освоения модуляций в процессе изучения гармонии. В контексте общей теории модуляции рассматриваются стилевые аспекты освоения модуляции. На основе стилевого подхода автор статьи предлагает иелостную систему ладотонального родства и разрабатывает новые способы модуляционных переходов в отдаленные тональности. Методология. Опираясь на традиционные теоретические концепции стиля (С. Скребков, М. Михайлов) и модуляции (И. Способин, Ю. Тюлин, Т. Бершадская, Ю. Холопов), разрабатывается метод стилевого анализа модуляционных процессов. $\mathbf{H a -}$ учная новизна заключается в теоретической разработке стилевого подхода к феномену модуляции в учебном курсе гармонии. Выводы. Стилевой подход к изучению модуляций способствует преодолению расхождения между теорией и практикой в преподавании гармонии и является одним из средств раскрытия художественного смысла музыкального произведения.

Ключевые слова: гармония, стиль, модуляция, мажоро-минорные системы.

Nivelt Olga, Ph.D. in History of Arts, professor of The Odessa National A. V. Nezhdanova Academy of Music, the department of the theory of music and composition

On the stylistic approach to the study of modulations in the university course of harmony

Objective. The article is devoted to the problem of mastering modulations in the process of studying harmony. In the context of the general theory of modulation, the stylistic aspects of mastering modulation are considered. On the basis of the style approach, the author of the article proposes an integral system of ladotonian kinship and develops new ways of modulation transitions to distant tonalities. Methodology. Based on the traditional theoretical concepts of style (S. Skrebkov, M. Mikhailov) and modulation (I. Sposobin, Yu. Tyulin, T. Bershadskaya, $Y$. Kholopov), a method of style analysis of modulation processes is developed. The scientific novelty lies in the theoretical development of the style

(C) Нивельт О. А., 2017 
approach to the phenomenon of modulation in the training course of harmony. Conclusions. The style approach to the study of modulations helps to overcome the discrepancy between theory and practice in teaching harmony and is one of the means of revealing the artistic meaning of a musical work.

Keywords: harmony, style, modulation, major-minor systems.

Нівельт Ольга Альфредівна, кандидат мистецтвознавства, приватпрофесор кафедри теорії музики та композиції Одеської національної музичної академії імені $А$. В. Нежданової

Про стильовий підхід до вивчення модуляцій у вузівському курсі гармонії

Мета статті. Статтю присвячено проблемі освоєння модуляцій в процесі вивчення гармонії. У контексті загальної теорії модуляції розглядаються стильові аспекти освоєння модуляції. На основі стильового підходу автор статті пропонує цілісну систему ладотональної спорідненості і розробляє нові способи модуляційних переходів у віддалені тональності. Методологія. Спираючись на традиційні теоретичні концепціі стилю (С. Скребков, М. Михайлов) та модуляції (І. Способін, Ю. Тюлін, T. Бершадська, Ю. Холопов), розробляється метод стильового аналізу модуляційних процесів. Наукова новизна полягає в теоретичній розробці стильового підходу до феномену модуляції в навчальному курсі гармонії. Висновки. Стильової підхід до вивчення модуляцій сприяє подоланню розбіжності між теорією і практикою в викладанні гармонії іє одним із засобів розкриття художнього змісту музичного твору.

Ключові слова: гармонія, стиль, модуляція, мажоро-мінорні системи.

Актуальность темы. Ставший достоянием музыкознания ноэтический метод анализа значительно расширил горизонты понимания художественных явлений музыкального искусства. Благодаря этому создались условия для совершенствования процесса обучения. В наибольшей степени это относится к курсу гармонии. Посредством привлечения стилевого подхода к изучению ее закономерностей представляется возможность углубить те представления о них, которые сложились в существующем учебном материале.

Цель статьи - теоретическая разработка целостной системы ладотонального родства и новых способов модуляционных переходов в отдаленные тональности на основе стилевого подхода.

Основное содержание. Стиль в музыке - это иерархическая структура стабильных музыкально-выразительных средств, отражающих образ мира определенных исторических эпох. Крупным планом различают эпохи: древности, средневековья, Нового и Новейшего времени. Главные стилевые показатели: лад, фактура, структура 
(С. Скребков), ритм (М. Михайлов). Их нужно привлекать к анализу гармонии в направленности на соотнесение технического и смыслового рядов.

В дополнение к сформулированным Скребковым основным принципам музыкального мышления - остинатности, переменности, централизирующего единства [7] мы относим поли- и децентрализацию, ведущие к закономерности множественности звуковысотных структур. На этой основе возникает значительное количество индивидуальных художественных решений, преломляющих свойства свободно-ассоциативного стиля (термин Г. Григорьевой).

В современной музыке функционирует интегрированный монодийно-полифонно-гармонический склад (термин Т. Бершадской). Гармония трактуется как звуковысотная структура (И. Способин, Ю. Холопов). Лад определяется как логически дифференцированная система субординационных и координационных отношений элементов (тонов, интервалов, аккордов, ладовых субсистем, т. е. ячеечных структур начального этапа музицирования, а также других моделей интонирования). Субординация - традиционный тип связи. Координация (от лат. со - совместно и ordinatio - упорядочивание) двусторонние субординационные отношения - балансирование (термин Б. Яворского).

Исходя из изложенного, в курсе стилевой гармонии три раздела: I - Модальная (ладомелодическая) система, II - Тональная (ладогармоническая) система, III - Взаимодействие модальных и тональных принципов звуковысотной организации. Теоретические основы курса изложены в исследовании «Общая теория функциональности в гармонии» [6].

Учитывая ограниченные рамки статьи, мы сосредоточим внимание на проблеме освоения модуляций, как одной из центральных тем данного курса, в наибольшей степени нуждающейся в расширенном понимании. Опираясь на общенаучное определение модуляции (от лат. modulatio - мерность, размеренность) - «закономерное изменение, перемена состояния» $[8,817]$, подчеркнем, что модуляции в музыковедении рассматриваются по отношению к тематизму, формообразованию, метроритму и так далее. В области ладового мышления модуляции относят к звуковысотности и характеризуют также неоднопланово. Например, существуют внетональные и межтональные образования (Ю. Тюлин), сплошные, сжатые, многозвенные типы модуляций (С. Слонимский). В. Золочевский в работе «О модуля- 
ции» различает их по протяженности и устойчивости тональных опор при анализе народной и профессиональной музыки в исторической перспективе, то есть во взаимодействии модальных и тональных особенностей звуковысотности [3].

В связи с этим целесообразно привести определение модуляции в словаре В. Даля: «Модуляция - переход из тона в тон» [2, 338]. Предложенная трактовка означает необходимость анализа процессов модального интонирования. Термин «модальность» (от лат. modus мера, правило, способ, предписание) в курсе стилевой гармонии применяется в широком значении, как принцип мышления в ладомелодической системе. Названная система нецентрализована. В ней господствует принцип переменности по существу (термин И. Истомина). В интонировании осуществляется смена функциональных значений тонов (опоры, неопоры, тоники, устоя), отражающая модуляционный процесс особого типа. В народных песнях с ячеечной структурой наблюдаются переходы из одной ячейки в другую. В рагах, мугамах и других подобных жанрах возникают модуляционные переключения попевок.

Знаменательно, что в модальной системе народного творчества происходит формирование ряда гармонических явлений. Качество нестабильности вертикальных структур содействует образованию секундовых отношений их основ. Д. Кастальский называет их рядовыми ступенями, В. Золочевский - смежноступенностью, а ходы баса на терцию и кварту в соединениях - ее нарушением. Так определяются функциональные отношения в натурально-ладовой гармонии. Таким образом, модальная и тональная системы находились во взаимодействии уже на ранних этапах развития.

Вопросы модуляции в ладогармонической системе в учебном материале представлены весьма противоречиво. На наш взгляд, наибольшего внимания заслуживает общая теория модуляции, содержащаяся во второй части учебника гармонии Ю. Тюлина [9]. Предложенная ученым классификация модуляций по типам выполнения и принципам родства достаточно убедительна. Четко определены разновидности модуляций по степени устойчивости, благодаря чему «снимаются» существующие в других учебниках разногласия. Различаются: совершенные модуляции (по протяженности и кадансовой закрепленности) и - несовершенные, существующие в двух вариантах: 1) модуляционное отклонение (незакрепленный переход с возвращением в исходную тональность), 2) проходящая модуляция 
(незакрепленный переход с продолжением процесса модулирования). Если возникает несколько модуляций с возвращением в первоначальную тональность, то образуется сложное отклонение.

По типам выполнения определены следующие виды модуляций:

1) функциональная, в которой происходит изменение функции общего аккорда в новой тональности;

2) энгармоническая, основанная на связи тональностей посредством общего аккорда, изменяющегося при переходе структурно и функционально;

3) мелодико-гармоническая модуляция, опирающаяся на мелодические связи аккордов. Мелодически подводящий аккорд из первой тональности соединяется с модулирующим, принадлежащим новой тональности;

4) мелодическая модуляция, в которой к новой тональности приводит мелодическое движение одного из голосов (часто дублируемого в двух и более голосах);

5) сопоставление - переход без соединительных элементов.

Тюлин также осуществляет четкую градацию изучаемых в учебном курсе тональностей по степеням родства. Опираясь на установку Н. Римского-Корсакова, он определяет наличие трёх степеней родства. К первой степени относятся тональности, тонические трезвучия которых входят в состав натурального и гармонического видов исходной. Ко второй степени принадлежат тональности, имеющие хотя бы одно общее трезвучие (но не тонику). Остальные тональности относятся отдаленному родству или к третьей степени.

В качестве дополнительных сведений автор ссылается на разницу в ключевых знаках и интервальные расстояния между тониками ладов. Знаменательно, что при модуляциях в тональности второй степени родства Тюлин, признавая возможность использовать общий аккорд как тонику промежуточной тональности, отдает предпочтение непосредственной связи тональностей через смену функционального значения общего аккорда. При поиске соединительных элементов для выполнения модуляций во вторую степень родства используется взаимное родство гармонической доминанты минора и гармонической субдоминанты мажора. Изложенные положения Тюлина о модуляциях позволяют осознанно освоить эту тему в курсе традиционной гармонии.

В стилевом курсе гармонии, в связи с изучением модальной и тональной систем в отдельности и во взаимодействии, представ- 
ления о тональном родстве значительно расширяются. Признавая факт необходимости развития теории о степенях родства тональностей, Т. Мюллер в своем курсе гармонии излагает суждения об этом различных авторов. Но отсутствие общих теоретических установок отодвигает время урегулирования названной проблемы. Мюллер заостряет внимание на том, что в учебниках гармонии разных музыковедов ко второй степени родства относятся тональности с разницей в два ключевых знака. В связи с этим он отмечает, что эти тональности «вовсе не ближе по родству, чем остальные восемь, что доказывается художественной практикой XIX и начала XX века; они значительно менеее употребительны, например, в экспозиционных частях» $[5,151]$.

По отношению к тонике C-dur разница в два ключевых знака присутствует тональностях B-dur и g-moll, принадлежащих миксолидийскому ладу, а также в D-dur и h-moll, относящихся к лидийскому варианту. Соответственно, к a-moll первые два трезвучия находятся во фригийском, вторые - в дорийском ладах. В произведениях с использованием натурально-ладовых средств в эпоху барокко, романтизма и в современной музыке трезвучия с разницей в два ключевых знака входят в состав лада, а тональности - относятся к первой степени родства. Так подтверждается идея о зависимости значений отдельных элементов и отношений между ними от типа системы.

Органичное применение натурально-ладовых средств можно наблюдать, например, в отрывке из оперы Дж. Пери «Эвридика». B a-moll дважды возникают отклонения в g-moll, тональность седьмой ступени фригийского лада. В первый раз переход в g-moll осуществляется путём повтора звука «с»: объединяющим элементом оказывается не аккорд, а тон. После этого применяется модулирующий аккорд: неполный доминантсептаккорд гармонического g-moll. Так происходит взаимодействие модальных и тональных средств ладообразования.

Второй переход в g-moll применён посредством последовательности аккордов E-dur и g-moll. Первый аккорд, закрепленный повторностью, не воспринимается как доминанта a-moll. Происходит сопоставление трезвучий разного наклонения с отсутствием общих тонов. Музыковед Я. Волек называет такой сдвиг медиантами второй степени, относя их к красочному типу связи, характерному для позднеромантической гармонии. При возвращении из g-moll в a-moll в конце отрывка в качестве соединительного элемента выступает ак- 
корд D-dur - трезвучие гармонической доминанты g-moll, которое приравнивается к дорийской субдоминанте a-moll, непосредственно разрешающейся в тонику.

В данном отрывке также используется присущий музыке барокко прием свободных замен мажорных и минорных тонических трезвучий a-moll и g-moll. Мы назвали это явление «вибрацией» мажоро-минора. Подобная взаимозаменяемость мажорных и минорных звучаний на уровне ладов в темах при формообразовании в творчестве венских классиков получила название «венского мажороминора» (термин В. Беркова). Например, в первой части Восьмой фортепианной сонаты Бетховена тема главной партии написана в c-moll. Побочная сфера включает две темы, первая из которых изложена в es-moll, вторая в Es-dur.

Описанные варианты сближения одноименных мажора и минора в творчестве романтиков увенчались слиянием их, как составных частей целого, в объединённых мажоро-минорных системах, в которых к одноименным добавились параллельные лады. Наиболее распространены малотерцовые мажоро-минорные циклы: полный (a-C-c), сокращенный (a-c) и усложненный (A-a-C-c). Дальнейшее расширение мажоро-минорных одноименно-параллельных связей приводит к образованию тритонового (a-C-c-Es) и полного циклов (a-C-c-Eses-Ges). В границах мажоро-минорных одноименно-параллельных циклов все входящие в них лады родственны. Конкретное количество участвующих ладов определяется композитором при сочинении художественных произведений. Развитие в них осуществляется путем свободного соединения их элементов. В дополнение к традиционному образуется особый тип модуляционных переходов.

Важными новыми функциональными оборотами в объединенных одноименно-параллельных ладах являются модифицированные варианты аутентических и плагальных функций. В мажор проникает гармоническая доминанта из параллельного минора. По отношению к тонике исходного мажора C-dur - это трезвучие E-dur, образующее аутентический каданс. Учитывая, что основной тон этой доминанты находится на третьей ступени, являющейся медиантой, полученный вариант каданса называется медиантовой доминантой. По отношению к тонике минора возникает, благодаря применению перед ней гармонической субдоминанты параллельного мажора, плагальный оборот под названием медиантовой субдоминанты. Это трезвучие f-moll к тонике a-moll, известное как аккорд VI «шубертовой» сту- 
пени. Играя выразительную роль «экспрессии краски» (определение Л. Мазеля), описанные кадансы в качестве функций высшего порядка расширяют представление о тональном родстве.

Показательно, что натуральную ладовость и черты одноименнопараллельного мажоро-минорного мышления в художественном творчестве можно проиллюстрировать на примере анализа определенных фрагментов в первой части Фортепианной сонаты Бетховена № 21 (op. 53). Тема главной партии, написанная в C-dur, в первом построении (такты 1-4) содержит модуляцию в G-dur. Секвентное повторение его смещается в B-dur с модуляцией в F-dur и f-moll. Таким образом, уже в начале произведения применён прием натуральноладового развития (B-dur - тональность седьмой ступени миксолидийского лада), а чередование мажоро-минорных трезвучий (F-dur, f-moll) отражает мажоро-минорные «вибрации» барокко. Тема побочной партии изложена в E-dur - тональности мажорной доминанты параллели (a-moll), то есть в тональности медиантовой доминанты к C-dur. B репризе тема побочной партии звучит в тональностях: A-dur - a-moll - C-dur. Здесь отражен одноименно-параллельный мажоро-минор A-a-C.

В одноименном мажоро-миноре на побочных ступенях появляются однотерцовые трезвучия (со смещением основного и квинтового тонов при сохранении терцового). Применение их в качестве тоники образует однотерцовый мажоро-минор. Подсоединение к одному из названных трезвучий (а возможно и к обоим) одноименных ладов создает однотерцово-хроматический мажоро-минор. В этой ладовой системе происходит уподобление диатоники и хроматики, устойчивости и неустойчивости, аутентичности и плагальности. Поэтому она называется энгармонической.

Пример ее применения можно обнаружить также в творчестве Бетховена. В разработке второй части Фортепианной сонаты № 27 (op. 90) фрагмент заключительной темы экспозиции проводится в следующих тональностях: C-dur - c-moll - cis-moll - Cis-dur, то есть композитор использует составные компоненты однотерцово-хроматического мажоро-минора.

Названные виды объединенных мажоро-минорных ладовых структур являются средством, с помощью которого можно объяснить сущностную сторону родства тональностей, относящихся у Тюлина к третьей степени родства. При их характеристике музыковед прибегает к использованию различий по количеству ключевых знаков и к указа- 
нию интервальных расстояний тоник. Привлекая изложенные положения о мажоро-минорных системах, можно объяснить принадлежность тональностей к третьей степени родства следующим образом: к C-dur относятся к данному типу родства cis-moll (однотерцовая к тонике), fis-moll (однотерцовая к субдоминанте), gis-moll (однотерцовая к доминанте), а также - Fis-dur (хроматическая к субдоминанте) и dis-moll (ее параллель). Подобная оценка присуща также тональностям, находящимся в третьей степени родства к минору. K a-moll это тональности: As-dur (однотерцовая к тонике), Des-dur (однотерцовая к субдоминанте), Es-dur (однотерцовая к доминанте), а также - esmoll (хроматическая к доминанте) и Ges-dur (ее параллель).

При выполнении модуляционных переходов в тональности третьей степени родства можно прибегать к традиционным средствам с участием двух промежуточных тональностей, как это советуют в учебных курсах. Но здесь отсутствует внутренний принцип связи. Предлагается механический подход через привлечение к исходному мажору тональности на полтона ниже, а к минору на полтона выше, как один из соединительных моментов. Можно выполнять переход мелодикогармоническим путем через доминантовый секундаккорд, обращение уменьшенного септаккорда VII ступени или альтерационного его варианта - как модулирующих аккордов, перед которыми применяются подводящие аккорды из начальной тональности. Но представленные переходы противоречат стилевому изучению модуляций.

Мы предлагаем такие способы связей тональностей третьей степени родства, которые органично отражают систему мажоро-минорного мышления. Связуюшими элементами являются медиантовая доминанта и медиантовая субдоминанта. Практика выполнения названных модуляций подтвердила возможность перехода во все тональности этой степени родства, причём может быть применён только один общий аккорд. При этом исходная и конечная тональности могут заменяться одноименными, поскольку медиантовые доминанта и субдоминанта в них совпадают. Например, медиантовая доминанта в C-dur (аккорд E-dur) будет ею и в c-moll, а медиантовая субдоминанта в a-moll (аккорд f-moll) присутствует и в A-dur.

Найденный общий аккорд берется третьим по счёту, как рекомендует Тюлин, чтобы услышать его принадлежность к первой тональности. Выбрать из обеих тональностей нужно такой аккорд, который является по отношению к одной из них медиантовой доминантой или медиантовой субдоминантой, а ко второй - трезвучием, содер- 
жащимся в натуральном или гармоническом ее звукоряде, то есть будет находиться к ней в первой степени родства. Предложенный переход осуществляется коротким путем, с участием всего пяти аккордов, то есть без длительных закреплений. Если тоника новой тональности окажется недостаточно опорной, ее можно закрепить модальным образом - повторением. Каданс к последней тонике может быть как аутентическим, так и плагальным. Например, если общий аккорд окажется медиантовой субдоминантой, то есть гармонией шестой «шубертовой» ступени, то выразительно прозвучит ее плагальное усложнение в виде «рахманиновской» гармонии.

В современной музыке возможны модуляции высшего порядка в виде перехода из одной ладовой структуры в другую. Подобное явление можно наблюдать в Прологе к балету Р. Щедрина «Анна Каренина». В сравнительно небольшом по протяженности разделе (до поднятия занавеса) содержатся три построения, иллюстрирующие различные типы звуковысотной организации. В первом из них (7 тактов до цифры 1) применена свободная атональность, что выражается в опорном значении тритона, малых и больших секунд. Во втором отрывке (13 тактов до цифры 2) музыкальная ткань расслаивается на три пласта, каждый из которых, опираясь на средства определенных этапов интонирования, входит в состав полипластовый фактуры, свойственной современной и позднеромантической музыке. В последнем эпизоде, в соответствии с установкой композитора на использование в балете инструментальной музыки П. Чайковского, совпадающей по времени написания с годами замысла и создания Л. Толстым романа «Анна Каренина», звучит лирико-драматический по жанру фрагмент из Второго квартета Чайковского, привлеченный для характеристики героини произведения.

Обобщая изложенное о балете, важно отметить, что осуществленное Щедриным обратное по отношению к историческому процессу эволюции ладотональности изложение музыкального материала в Прологе (от атональности через полипластовость к централизованной системе), можно трактовать как способ претворения характерного для театра Б. Брехта приема отчуждения, смысл которого состоит в стремлении направить восприятие зрителей и слушателей на постижение авторского замысла.

Выводы. Таким образом, стилевой подход к изучению модуляций способствует преодолению расхождения между теорией и практикой 
в преподавании гармонии и является одним из средств раскрытия художественного смысла музыкального произведения.

\section{СПИСОК ЛИТЕРАТУРЫ}

1. Бершадская Т. С. Лекции по гармонии. Л.: Музыка, 1985. 238 с.

2. Даль В. И. Толковый словарь живого великорусского языка. М.: Госиздат иностранных и национальных словарей, 1955. Т. 2. 780 с.

3. Золочевський В. Н. Про модуляцію. Київ: Музична Україна, 1972. $283 \mathrm{c}$.

4. Иванов-Борецкий М. В. Музыкально-историческая хрестоматия. М.: Музгиз, 1936. Вып. 2. 212 с.

5. Мюллер Т. Ф. Гармония. М.: Музыка, 1982. 288 с.

6. Нивельт О. А. Общая теория функцональности в гармонии. Одесса: Друкарський дім, 2007. 224 с.

7. Скребков С. С. Художественные принципы музыкальных стилей. М.: Музыка, 1973. 448 с.

8. Советский энциклопедический словарь. М.: Советская Энциклопедия, 1983. $1600 \mathrm{c}$.

9. Тюлин Ю. Н. Учебник гармонии. Часть II. М.: Музгиз, 1959. 200 с.

\section{REFERENCES}

1. Bershadskaya, T. S. (1985). Lectures on Harmony. Leningrad.: Music [in Russian].

2. Dahl, V. (1955). Explanatory Dictionary of the Living Great Russian Language. Moscow: State Publishing House for Foreign and National Dictionaries. Vol. 2 [in Russian].

3. Zolochvsky, V. N. (1972). About modulation. Kiev: Muzychna Ukraine [in Ukrainian].

4. Ivanov-Boretsky, M. V. (1936). Musical-historical reader. Moscow: Muzgiz, Vol. 2 [in Russian].

5. Mueller, T. F. (1982). Harmony. Moscow: Music [in Russian].

6. Nivelt, O. A. (2007). The general theory of functionality in harmony. Odessa: The Printing House [in Ukrainian].

7. Skrebkov, S. S. (1973). Artistic principles of musical styles. Moscow: Music [in Russian].

8. Soviet Encyclopedic Dictionary (1983). Moscow: Soviet Encyclopedia [in Russian].

9. Tyulin, Y. N. (1959). Textbook of Harmony. Part II. Moscow: Muzgiz [in Russian].

Стаття надійшла до редакції 1.03.2017

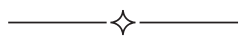

